ORIGINAL STUDY

\title{
Polysomnography outcomes on patients with obstructive sleep apnea after upper airways repermeabilization surgery
}

\author{
Ionut Tanase ${ }^{1,3}$, Claudiu Manea ${ }^{1,2,3}$, Codrut Sarafoleanu ${ }^{1,2,3}$ \\ ${ }^{1}$ ENT\&HNS Department, "Sfanta Maria" Hospital, Bucharest, Romania \\ 2"Carol Davila" University of Medicine and Pharmacy, Bucharest, Romania \\ ${ }^{3}$ CESITO Centre, "Sfanta Maria” Hospital, Bucharest, Romania
}

\begin{abstract}
BACKGROUND. Sleep apnea is a pathology with an ever-increasing spread, the causes being the most diverse. In this study we focus on sleep breathing disorders caused by nasal obstruction and also by soft palate and uvula anatomical changes. The right treatment recommended in this pathology according to the American Academy Sleep Medicine (AASM) is non-invasive ventilation - positive airway pressure (CPAP). A substantial percentage of patients with obstructive sleep apnea seek alternatives to CPAP and the solution for this can be upper airway surgery.

OBJECTIVE. The attempt to demonstrate the viability of upper respiratory tract surgery as an alternative to CPAP treatment, demonstrating objectives by pre- and postoperative polysomnographic control.

RESULTS. Aggregating the data from all 54 patients with nasal obstruction and pharyngeal modifications, we observed a decrease in AHI from 20.406/h to 15.86/h, representing 32.36\%, an improvement in sleep architecture and especially REM sleep from 41.5 minutes initially to 67.8 minutes (increased value with 63.37 percent).

CONCLUSION. The benefits of nasopharyngeal repermeabilization surgery are represented by decreasing the severity of respiratory events and, second to this, lowering the number of arousals. By reducing the number of arousals, one will obtain a better percentage regarding the deep sleep phase - REM, having a beneficial effect on reducing the daytime sleepiness - which is a major symptom that patients are present.
\end{abstract}

KEYWORDS: sleep apnea, polysomnography, LAUP, nasal repermeabilization surgery.

\section{INTRODUCTION}

In the last years, we observed that obstructive sleep apnea (OSA) has had an increased prevalence, and more that $6 \%$ of women and $13 \%$ of men from USA are diagnosed with this pathology ${ }^{1}$.

In order to manage this disorder, the non-invasive ventilation with continuous positive airway pressure (CPAP) is considered the gold standard therapy ${ }^{2}$.

A considerable percentage of the patients with obstructive sleep apnea failed to respond following the treatment with positive airway pressure therapy and so turned to various surgical procedures for the resumption of the respiratory flow ${ }^{3}$. The effectiveness of the surgical procedures regarding the different sites of the upper airway tract obstruction is questioned, but we believe that proper patient selection and also realistic expectations can increase the quality of life and reduce the sleep disorder episodes ${ }^{4}$.

\section{MATERIAL AND METHODS}

In our clinic, we developed a prospective study conducted between October 2015 and January 2018 , in which we tried to demonstrate the influence onto sleep fragmentation and REM sleep phases of the ENT repermeabilization surgery of the upper respiratory tract.

Every patient admitted to the ENT Department of "Sfanta Maria" Hospital with sleep disorder was evaluated and we used the exclusion and inclusion 


\section{Table 1}

Symptoms and signs of OSA in the daytime and night-time.

\begin{tabular}{|c|c|}
\hline Diurnal Symptoms of OSA & Nocturnal manifestations of OSA \\
\hline Excessive daytime sleepiness & $\begin{array}{l}\text { Intense persistent snoring } \\
\text { increased in supine position or } \\
\text { after alcohol intake or sedatives }\end{array}$ \\
\hline $\begin{array}{l}\text { Incapacity to concentrate and } \\
\text { memory dysfunction }\end{array}$ & $\begin{array}{l}\text { Apnea with limb movement, } \\
\text { witnessed by the bed partner }\end{array}$ \\
\hline Sexual impairment & $\begin{array}{l}\text { Sudden awakening with noisy } \\
\text { breathing }\end{array}$ \\
\hline Gastroesophageal reflux & Accidents correlated to sleepiness \\
\hline \multirow[t]{3}{*}{$\begin{array}{c}\text { Behavioural changes (irritability, } \\
\text { depression, chronic fatigue, } \\
\text { delirium) }\end{array}$} & Nocturnal perspiration \\
\hline & $\begin{array}{l}\text { Sensation of dry mouth when } \\
\text { waking up }\end{array}$ \\
\hline & Nycturia \\
\hline
\end{tabular}

criteria further detailed:

- exclusion criteria: substantial facial deformity such as retrognathia, patients with apnea of either neurologic or pulmonary origin, every patient diagnosed with severe apnea whose adequate indication was represented by home treatment with non-invasive ventilation.

- inclusion criteria were represented by: nasal obstruction of various causes (for example, deviation of the nasal septum, chronic hypertrophic rhinitis); pharyngeal pathology (elongated soft palate and/or uvula, tonsils hypertrophy, etc.).

The patients included in the study presented one or more symptoms and signs of OSA in the daytime, but also during the night (Table 1).

The diagnosis of the sleep apnea syndrome was performed with objective measurements - polysomnographic (PSG) evaluation, drug-induced sleep endoscopy, radio-imagistic evaluation (like the cephalometric analysis), and subjective evaluation by using the Epworth Sleepiness Scale.

In case of PSG, in order to objectify the various sleep stages, we used standard electroencephalographic (EEG), electromyographic (EMG), and electro-oculographic (EOG) criteria. Based on AASM recommendations, 16 EEG was recorded with electrodes fixed at C3-A2 and C4-A1 and the EMG activity was monitored from the anterior tibialis muscles and submental muscles ${ }^{5}$. We used a fully equipped system of Alice 6 LDX to investigate and diagnose sleep disorders.

Apnea is described as airflow discontinuity at the level of the nose and the mouth that lasts more than 10 seconds and which is objectified by using

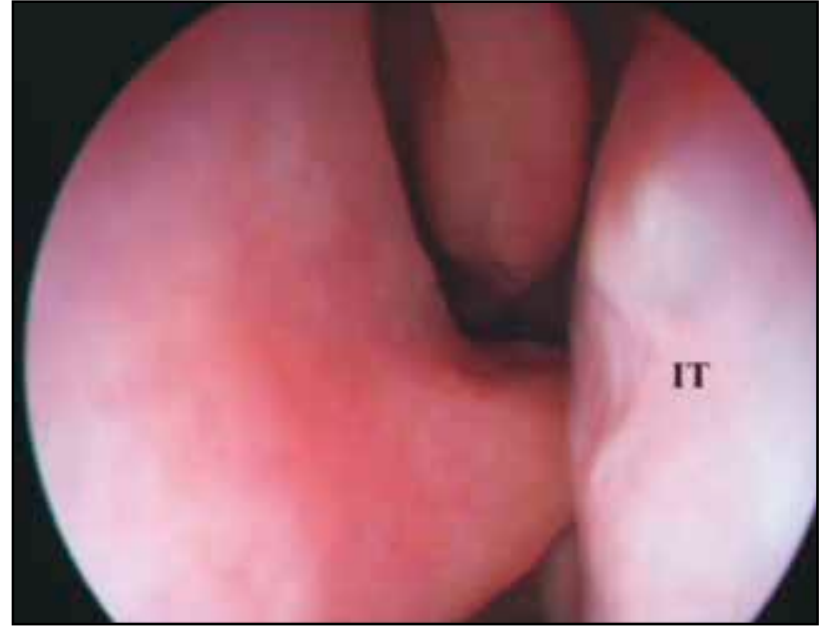

Figure 1 Nasal septum deviation.

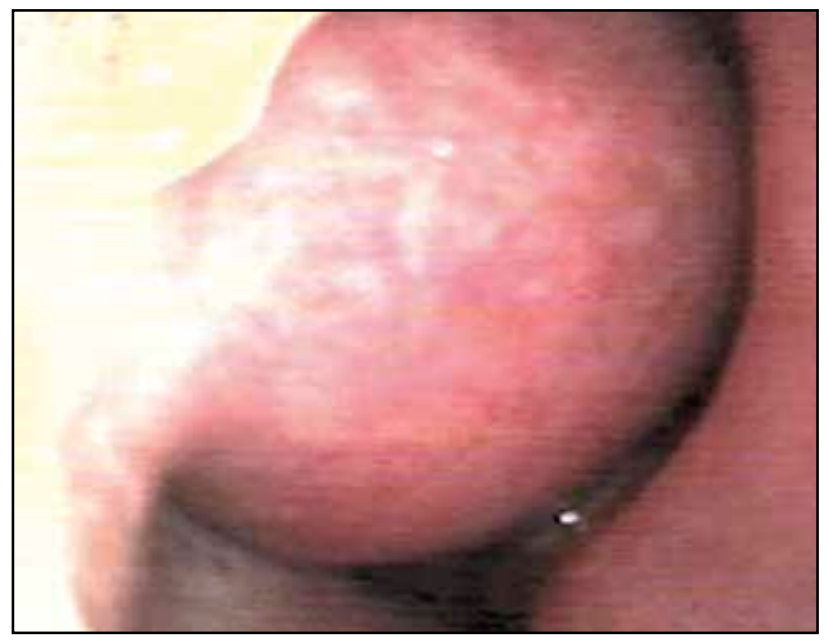

Figure 2 Inferior turbinates hypertrophy.

an infrared CO2 analyser, that has the purpose to record from both the nose and the mouth and a pulsoxymetric sensor that records the level of oxygen saturation from the index finger ${ }^{6,7}$.

Hypopnea is represented by a decline of more than $50 \%$ in the excursion of the sum channel of a respiratory inductance plethysmography measuring chest wall and abdominal movement ${ }^{6,7}$.

A single electrocardiographic (ECG) lead (modified V2) is used to monitor cardiac activity.

For an accurate result we manually evaluated the complete recorded night investigation for sleep stage and apnea type and duration. An index of apnea and hypopnea over one hour is correspondent to the severity of index of respiratory events (AHI). Also, on EEG activity we evaluated the prevalence of arousals ${ }^{8}$.

In order to assess the recurrence of snoring epi- 
Table 2

PSG results before and after LAUP for OSA.

\begin{tabular}{|c|c|c|c|c|}
\hline \multirow[t]{2}{*}{ OSA patients } & \multicolumn{2}{|c|}{ Mean AHI } & \multicolumn{2}{|c|}{ Min Sp02 } \\
\hline & Preoperatory & Postoperatory & Preoperatory & Postoperatory \\
\hline Total (n-31) & 18.84 & 14.31 & 85.89 & 87.6 \\
\hline OSA severe $(n-7)$ & 42.6 & 39.3 & 77.5 & 81.4 \\
\hline OSA moderate (n-14) & 14.5 & 9.4 & 87.3 & 88.2 \\
\hline OSA mild (n-10) & 8.3 & 3.7 & 89.8 & 91.1 \\
\hline
\end{tabular}

sodes, a microphone was placed onto the laryngeal region. Other parameters that were evaluated during this procedure were: respiratory distress thoracic and abdominal motion via strain gauges, piezoelectric belts, inductive plethysmography, impedance or inductance pneumography, endoesophageal pressure, or by intercostal EMG; airflow at the level of the nose and the oral cavity - thermistor or pneumotachograph; mercury switches or direct observation were used to determine body position; limb movements (arms and legs) ${ }^{9}$.

54 patients diagnosed with obstructive sleep disorders were enrolled, 21 women and 33 men. All these subjects performed an initial polysomnography that revealed one of the levels of the sleep apnea. Out of them, 42 refused the CPAP therapy and 12 had a poor adherence to positive air pressure and were redirected to surgical procedures.

The severe forms of OSA ( 5 patients) and 12 of the moderate sleep apnea patients were directed to the CPAP titration in order to analyze the improvement which can be achieved after the surgery. All the patients performed a polysomnography 6 months after the surgery to evaluate the surgical result.

The rhinomanometry test and the nasal endoscopy were used to assess, pre- and postoperatively, the nasal permeability. The anatomical causes of
Table 3

CPAP titration levels before and after LAUP for OSA.

\begin{tabular}{ccc}
\hline OSA patients & \multicolumn{2}{c}{ Mean CPAP $(\mathbf{c m H 2 0})$} \\
\hline & Preoperatory & Postoperatory \\
\hline Total $(\mathrm{n}-17)$ & 8.6 & 7.5 \\
\hline OSA severe $(\mathrm{n}-5)$ & 11.2 & 8.2 \\
\hline OSA moderate $(\mathrm{n}-12)$ & 8.6 & 7.2 \\
\hline
\end{tabular}

nasal obstruction may be different, but the patients that we enlisted in this study suffered from nasal septum deviation (Figure 1), inferior turbinates hypertrophy (Figure 2) or both of them - 23 patients out of 54, aged between 23 and 65 years old. Subjects known with chronic rhinosinusitis were not included in this study.

The rest of 31 patients presented pharyngeal obstruction due to long soft palate and uvula.

All patients diagnosed with nasal obstruction underwent repermeabilization of the nasal fossae by septoplasty, inferior turbinates volume reduction (partial mucotomy or radiofrequency turbinoplasty) or both of them.

In the case of patients diagnosed with pharyn-

Table 4

PSG results before and after nasal surgery for OSA.

\begin{tabular}{ccccc}
\hline OSA patients & \multicolumn{2}{c}{ Mean AHI } & \multicolumn{2}{c}{ Min Sp02 } \\
\hline & Preoperatory & Postoperatory & Preoperatory & Postoperatory \\
\hline Total $(\mathrm{n}-23)$ & 22.49 & 17.97 & 85.36 & 86.99 \\
\hline OSA severe $(\mathrm{n}-5)$ & 52.7 & 47.3 & 78.5 & 80.6 \\
\hline OSA moderate $(\mathrm{n}-12)$ & 16.5 & 12.4 & 86.2 & 88.1 \\
\hline OSA mild $(\mathrm{n}-6)$ & 9.3 & 4.7 & 89.4 & 90.1 \\
\hline
\end{tabular}




Table 5
CPAP titration levels before and after nasal surgery
for OSA.
\begin{tabular}{ccc} 
& & \\
\hline OSA patients & \multicolumn{2}{c}{ Mean CPAP $(\mathbf{c m H 2 0})$} \\
\hline \multicolumn{4}{c}{ Preoperatory } & Postoperatory \\
\hline Total $(\mathrm{n}-17)$ & 9.6 & 8.5 \\
\hline OSA severe $(\mathrm{n}-5)$ & 10.4 & 7.2 \\
\hline OSA moderate $(\mathrm{n}-12)$ & 8.2 & 6.8 \\
\hline
\end{tabular}

geal obstruction, laser-assisted uvulopalatoplasty (LAUP) was performed.

The preoperative and the 6-month postoperative polysomnography result data regarding sleep symptoms and nasal obstruction were compared. We analyzed the following parameters: AHI, maximum duration of an obstructive respiratory event, sleep distribution (REM sleep percentage), SpO2, arousals and snoring episodes.

\section{RESULTS}

Analysing the data from all 31 patients diagnosed with pharyngeal obstruction due to long soft palate and uvula, for which LAUP was performed, we summarised the pre- and the 6-month postoperative PSG results. We observed in all stages of apnea an improvement in the AHI, but better results were recorded in patients with moderate and mild sleep apnea syndrome (Table 2). Also, an improvement in the minimum $\mathrm{SpO} 2$ values was obtained.

Regarding the CPAP titration levels, we observed that the CPAP mean pressure decreased after LAUP in both moderate and severe sleep apnea syndromes (Table 3 ).

Out of the 54 patients evaluated pre- and postoperatively, 23 underwent nasal repermeabilization procedure. For this batch of patients, the mean preoperative AHI was 22.49 and it was improved by approximately $21 \%$, reaching a level of 17.94. We observed that in all stages of apnea we obtained an improvement in the AHI, but better results were recorded in patients with moderate and mild sleep apnea syndrome (Table 4). Also, an improvement in the minimum SpO2 values was obtained.

Patients with mild and moderate forms of OSA had satisfactory results following the procedure, while patients with severe forms had better results in what the CPAP therapy is concerned. The CPAP pressure registered a decrease in the mean pres-

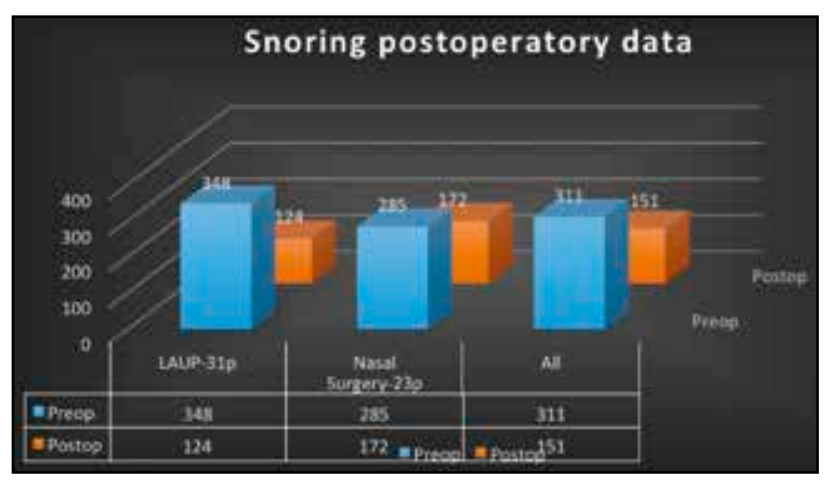

Figure 3 Snoring postoperatory data.

sure from $10.4 \mathrm{mmHg}$ to $7.4 \mathrm{mmHg}$ (Table 5). We noted that, in both cases, severe/moderate OSA, the therapeutic CPAP pressure decreased, fact that improved the compliance with the treatment.

After the LAUP surgery performed on the 31 patients with pharyngeal obstruction, from a total of 348 events of snoring we obtained 124 events. In the case of those 23 patients on whom nasal surgery was performed, we observed a decrease in snoring events from 285 initially to 172 (Figure 3 ). So, we noticed that after LAUP we have better results than after nasal repermeabilization surgery in the case of snoring.

On the entire study group, a decreased snoring index was recorded, with a total number of 151 events after surgery from 311 events initially (Figure 3).

Aggregating the data from all 54 patients with nasal obstruction and pharyngeal modifications, we observed a decrease in the mean AHI from $20.406 / \mathrm{h}$ to $15.86 / \mathrm{h}$ (representing $32.36 \%$ ), an improvement in the sleep architecture and especially REM sleep from 41.5 minutes initially to 67.8 minutes (increased value with 63.37 percent) (Figure 4 ). The analysis of sleep stages was very important because many patients complained of daytime

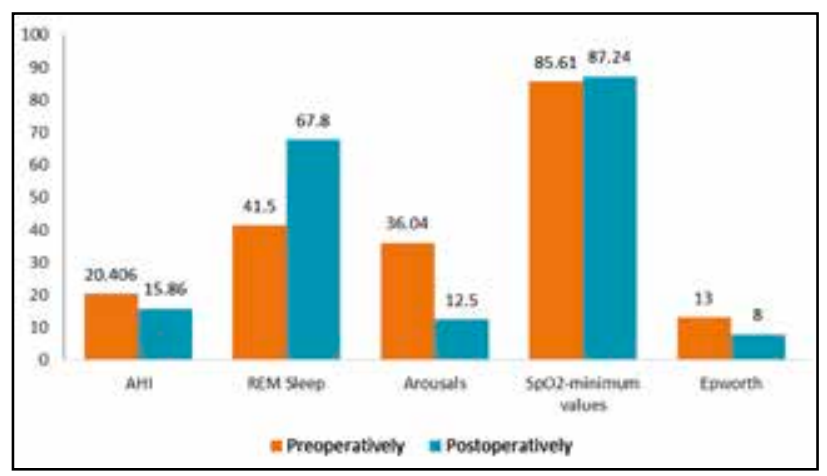

Figure 4 6-month postoperative PSG results and Epworth Scale Score. 
sleepiness before surgery, fact due to sleep fragmentation. In the case of those patients with nasal obstruction, we saw a real improvement in REM sleep distribution. The REM sleep improved from a preoperative mean of 48.2 minutes to 73 minutes postoperatively.

The "first-night" effect impact on the accuracy of the polysomnography can be taken into consideration regarding the difference between preoperative and postoperative REM sleep.

The most important fact that influenced the sleep distribution was represented by the decrease in arousals, from an initial value of $36.04 / \mathrm{h}$ to a postoperative index of $12.5 / \mathrm{h}$ (Figure 4). As we know, sleep fragmentation is directly influenced by the appearance of arousals.

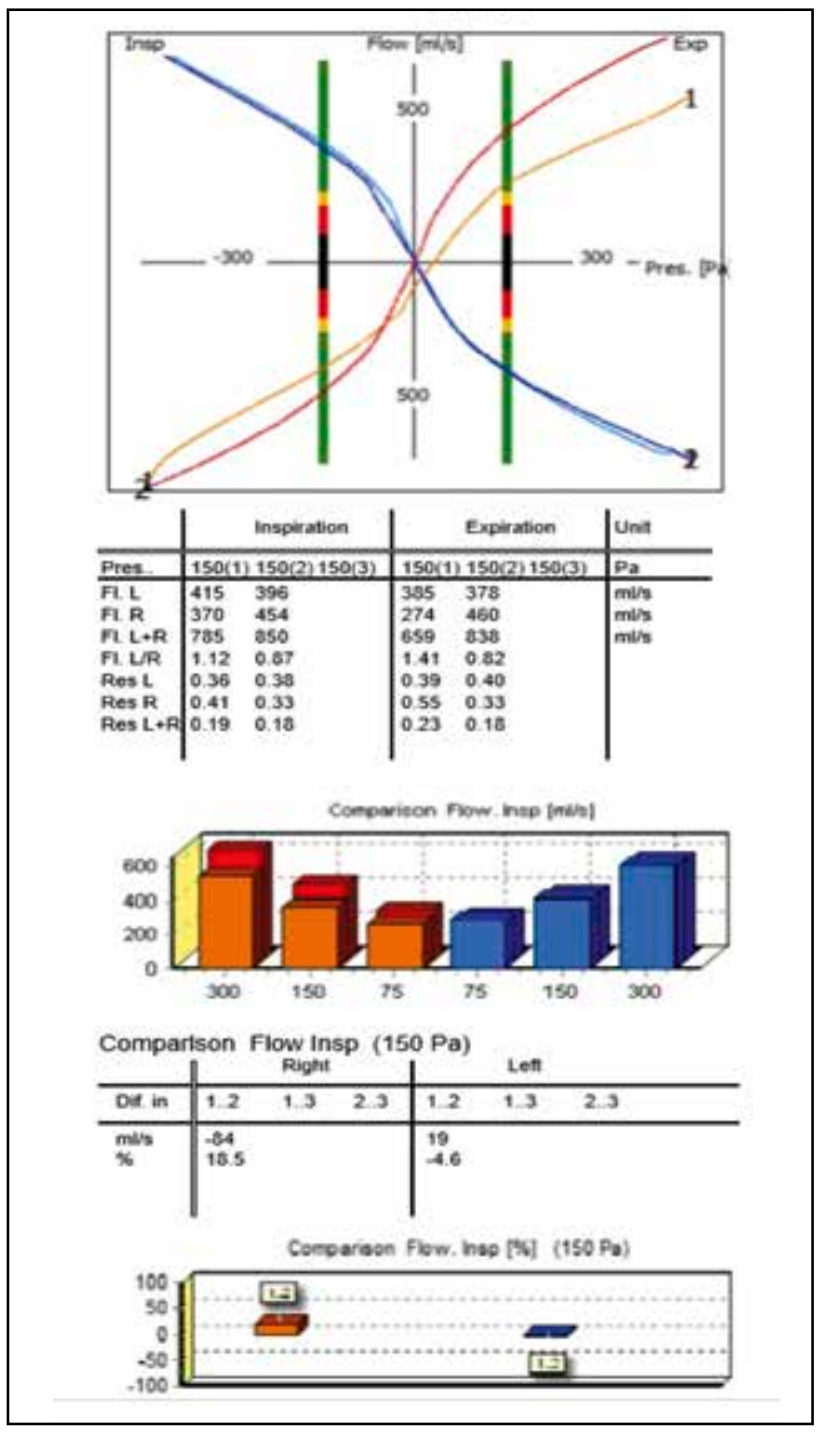

Figure 5 Anterior rhinomanometry performed before surgery moderate nasal obstruction of the left fossa and mild obstruction of the right nasal fossa - obstructive nasal septum deviation and hypertrophy of the inferior turbinates mucosa.
Also, the decrease in arousal index allows the patients to obtain periods of uninterrupted sleep, which may be sufficient to overcome any daytime dysfunction that may have occurred due to their REM or posture-related sleep apnea.

Another important aspect that we focused on was the lowest value of the $\mathrm{SpO} 2$ that presented an important increase from $85.61 \%$ initially to $87.24 \%$ (Figure 4). This is conditioned by the shorter periods of respiratory events.

Daytime sleepiness was subjectively assessed using the Epworth questionnaire; from 13 points initially to 8 points postoperatively (Figure 4 ).

All of this data encourages us to believe that although nasal and LAUP reperfusion surgery cannot always have a curative visa, they can success-

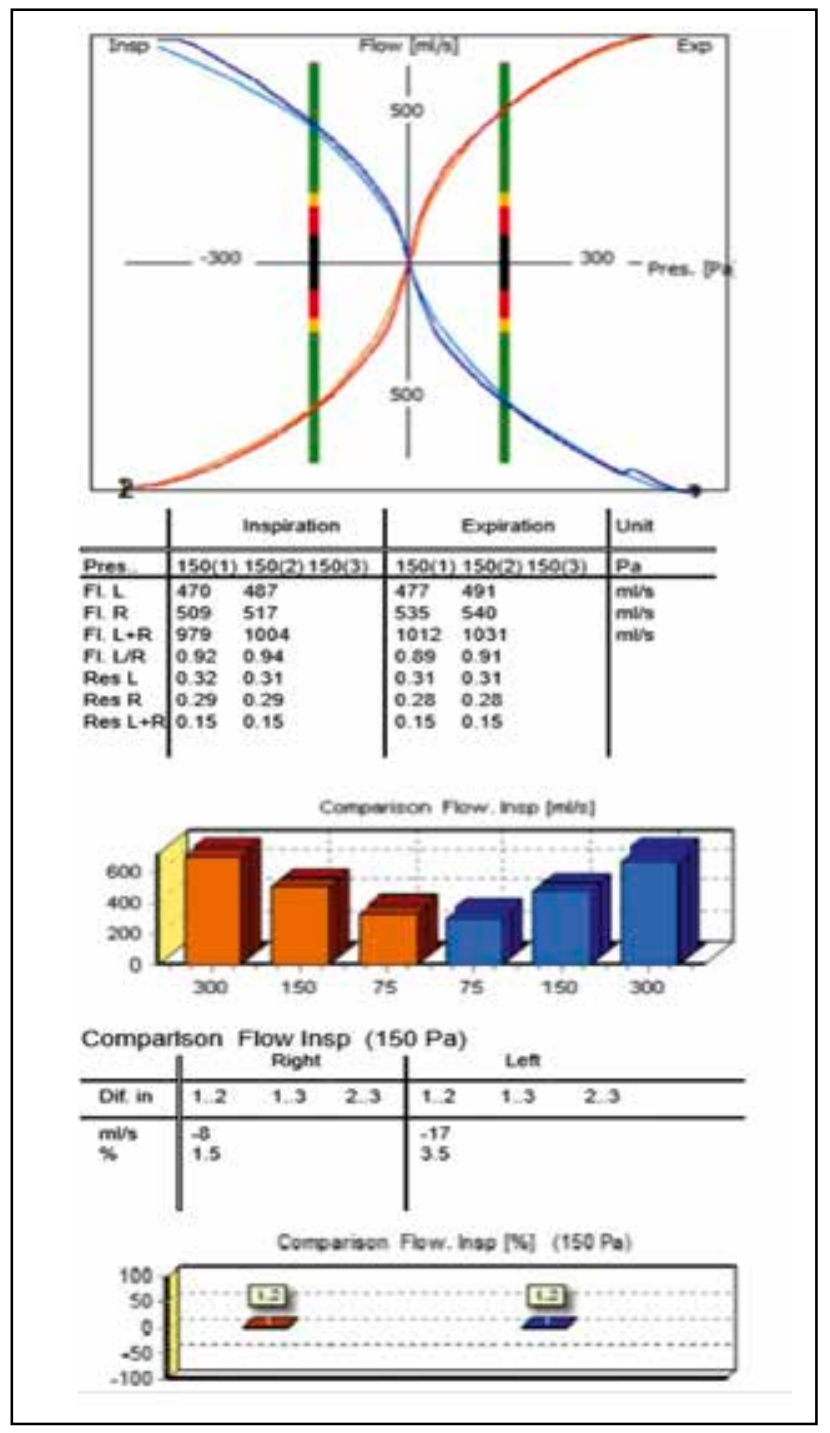

Figure 6 Anterior rhinomanometry 1 month after surgery - no nasal obstruction. 


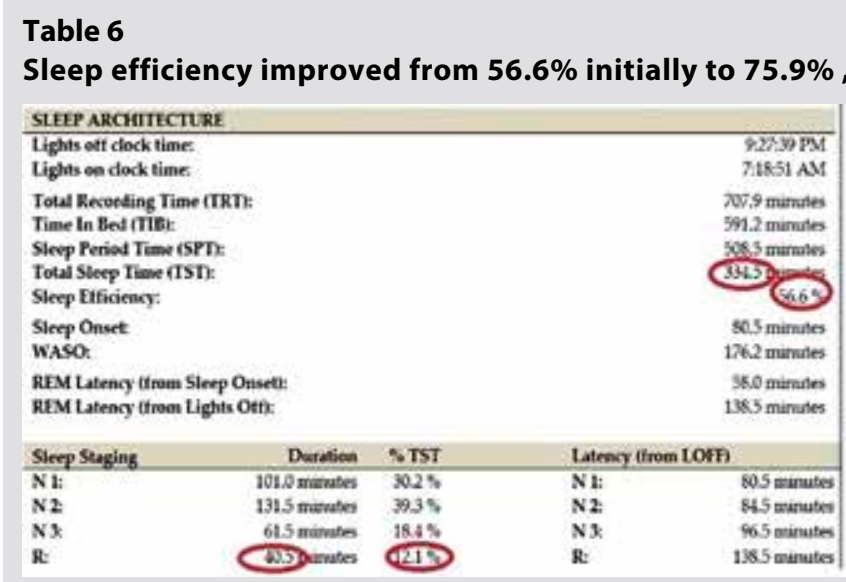

\begin{tabular}{|c|c|c|c|c|}
\hline \multirow{2}{*}{\multicolumn{4}{|c|}{ lights on doxk tien. }} & $9.55 \times 15 \mathrm{FM}$ \\
\hline & & & & GS52AMM \\
\hline \multicolumn{4}{|c|}{ 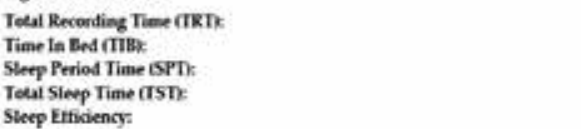 } & $\begin{array}{l}565.7 \text { minutes } \\
599.9 \text { minutes } \\
565 \text { mirutes } \\
4175 \text { gauter }\end{array}$ \\
\hline \multicolumn{4}{|l|}{$\begin{array}{l}\text { Sheep Onat: } \\
\text { WASO: }\end{array}$} & $\begin{array}{l}200 \text { minutes } \\
\text { s04 minuter }\end{array}$ \\
\hline \multicolumn{3}{|c|}{ 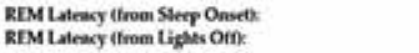 } & & $\begin{array}{l}665 \text { menutes } \\
1075 \text { minutes }\end{array}$ \\
\hline Stuep Staging & Durution & * TST & Later & \\
\hline N1: & 124.5 mirntes & 32.05 & N1: & 20 minuter \\
\hline $\mathrm{N} 2$ & 2150 mirnses & 52.25 & $\mathrm{~N} 2$ & 660 mansent \\
\hline Ns: & 35 mirnotes & $0.8 \%$ & $\mathrm{~N} 3 \mathrm{.}$ & 770 minutes \\
\hline E. & (12) nirmeses & 169 & Be & 1065 mencues \\
\hline
\end{tabular}

Table 7

Arousal index decreased from $\mathbf{2 8 . 8}$ to $\mathbf{1 9 . 1}$

AROUSAIS

\begin{tabular}{|c|c|c|c|c|c|c|}
\hline & REM & NREM & Arousals & Avakenings & $A x+A w$ & $\begin{array}{c}A x+A w \\
\text { Ledex }\end{array}$ \\
\hline Respintory: & 0 & 64 & 67 & 38 & 105 & 147 \\
\hline Leg Movement & 0 & 22 & 22 & 18 & $\$ 0$ & 56 \\
\hline Snece: & 0 & 8 & 8 & 10 & 15 & 25 \\
\hline Spentaseous & 0 & 20 & 24 & 19 & 43 & 60 \\
\hline Total: & 0 & 114 & 121 & 85 & 206 & 288 \\
\hline Apousal Index & $\infty$ & 159 & 169 & 119 & C85B & $=$ \\
\hline
\end{tabular}

AROUSALS

\begin{tabular}{|c|c|c|c|c|c|c|}
\hline & REM & NREM & Arousils & Awakenings & $A t+A w$ & $\begin{array}{l}A x+A w \\
\text { Index }\end{array}$ \\
\hline Respiratery: & 12 & 7 & 19 & 10 & $\boldsymbol{z}$ & 42 \\
\hline Leg Movement & 3 & 2 & 26 & 8 & अ & 49 \\
\hline Snope: & 0 & 1 & 1 & 3 & 4 & 0.6 \\
\hline Spontaneosex & 9 & 18 & 23 & 36 & 66 & 95 \\
\hline Toult: & 24 & 48 & 74 & 99 & 133 & 19.1 \\
\hline Arowall badec & 157 & 8.8 & 10.6 & 85 & (19) & - \\
\hline
\end{tabular}

fully treat patients suffering from respiratory disorders during sleep in carefully selected cases. Also, better postoperative outcomes were obtained by weight loss after both types of surgery. This might be one of the reasons for the differences occurring in the final results.

To sustain our study results, we present two cases chosen from the patients included in the presented study.

\section{Case 1}

A 37-year-old patient was admitted to our clinic for intermittent bilateral nasal obstruction, snoring and sleep apnea (both reported by the entourage), decreased working capacity, epileptic somnolence. The Epworth Score was 14. The symptoms debuted several years ago with progressive aggravation, concomitant with weight gain (approximately $15 \mathrm{Kg}$ over the last 3 years; $\left.\mathrm{BMI}=30.6 \mathrm{Kg} / \mathrm{m}^{2}\right)$. The patient was hospitalized for specialized investigations - polysomnography.
The ENT clinical evaluation revealed obstructive nasal septum deviation (type II) on the left side, inferior turbinates hypertrophy, without any sinusal pathology and rhino/oro/hypopharynx in normal condition. The vocal folds were mobile, supple, without pathological changes.

The rhinomanometric evaluation performed before surgery revealed a reduction of the inferior turbinates mucosa after anemization with vasoconstrictor solutions (Figure 5).

The initial polysomnographic test revealed a moderate sleep apnea, with an AHI of $21.6 / \mathrm{h}$, REM sleep $=40.5 \mathrm{~min}, 206$ micro-treatings with an index of $28.8 / \mathrm{h}$, and a sleep efficiency of $56.6 \%$.

In order to obtain the nasal repermeabilization, we performed septoplasty and radiofrequency turbinate reduction under general anaesthesia. The nasal packing was removed after 24 hours. After 1 month we performed the control tests, using the anterior rhinomanometry that revealed an important improvement in the airflow and nasal resistance (Figure 6).

After 6 months we performed a polysomnography to evaluate the sleep events after surgery (Tables 6-9).

The preoperative AHI improved by $18 \%$ from $21.4 / \mathrm{h}$ initially to $17.6 / \mathrm{h}$ (Table 8 ). The minimum SpO2 was improved from $81 \%$ initially to 92\% (Table 9). Arousals decreased from a total of 28.8 to $19.1 / \mathrm{h}$ (Table 7 ). Snoring episodes also went through an important decrease from 186 events to 36 events. The sleep architecture and especially the deep sleep - REM improved from 40.5 minutes initially $(12.1 \%)$ to $71.5 \mathrm{~min}$ utes $(14.9 \%)$ (Table 6$)$.

An important argument was also the subjective perception and for that we used the Epworth questionnaire to evaluate the results of the repermeabilization nasal surgery results. From a medium of 14 
Table 8

The total number of respiratory events decreased from 149 events to 98 events, the initial AHI of $21.4 / \mathrm{h}$ improved to $17.6 / \mathrm{h}$.

\begin{tabular}{|c|c|c|c|c|c|c|c|c|}
\hline & $\mathrm{CA}$ & OA & MA & Apoea & Itweeg: & $\mathbf{A}+\mathbf{H}$ & RERA & Total \\
\hline Number: & 0 & (II) & 0 & 41 & 108 & 149 & 0 & (149) \\
\hline Mean Dur Gect: & 0.0 & 14.5 & 0.0 & 145 & 20.3 & 15.7 & 0.0 & 18.7 \\
\hline Max Dast (bet: & 0.0 & 25.0 & 0.0 & 250 & 57.5 & & 90 & 57.5 \\
\hline Total Dur (min) i & 0.0 & 93 & 0.0 & 93 & 365 & 464 & 00 & 464 \\
\hline Sof TST: & 0.0 & 24 & 0.0 & 24 & 87 & 11.1 & 00 & 11.1 \\
\hline Index (Ah TST) : & 0.0 & 5.9 & 0.0 & 5.9 & 15.5 & 21.4 & 00 & 21.4 \\
\hline REM Count: & 0 & 23 & 0 & 23 & 49 & $\bar{n}$ & 0 & $\pi$ \\
\hline NREM Comnt: & 0 & 18 & 0 & 18 & 59 & $\pi$ & 0 & $\pi$ \\
\hline REM Index: & 0.0 & 15.1 & 0.0 & 15.1 & 32.1 & 47.2 & 90 & 972 \\
\hline NREM IASEC & 0.0 & 33 & 0.0 & 3.3 & 109 & 16.2 & 00 & 14.2 \\
\hline
\end{tabular}

\begin{tabular}{|c|c|c|c|c|c|c|c|c|}
\hline & CA & OA & MA & Apnes & Hypep" & $A+B$ & RERA & Total \\
\hline Number: & 0 & (2) & 0 & 25 & $(75)$ & 98 & 0 & $\cos$ \\
\hline Mean Dur (seck & 0.0 & 20.9 & 0.0 & 20.9 & 24.2 & 23,4 & 0.0 & 234 \\
\hline Max Dex Gect: & 0.0 & 420 & 0.0 & 420 & 590 & 909 & 0.0 & 59.0 \\
\hline Total Dur (min) : & 0.0 & 87 & 0.0 & 87 & 20.5 & 32 & 0.0 & 302 \\
\hline Sof TST: & 0.0 & 26 & 00 & 26 & 8.8 & 11.4 & 0.0 & 11.4 \\
\hline Index ( $(W h$ TSD) : & 0.0 & 45 & 00 & 4.5 & 13.1 & 17.6 & 0.0 & 17.6 \\
\hline REM Count: & 0 & 1 & 0 & 1 & 6 & 7 & 0 & 7 \\
\hline NREM Coent: & 0 & 24 & 0 & 24 & 67 & 91 & 0 & 91 \\
\hline REM Index & 0.0 & 15 & 0.0 & 15 & 8.9 & 10.4 & 0.0 & 104 \\
\hline NREM ladex & 0.0 & 49 & 0.0 & 4.9 & 13.7 & 186 & 0.0 & 18.6 \\
\hline
\end{tabular}

Table 9

Snoring episodes decreased from 186 to 36 events and the minimum SpO2 improved from 81 to $92 \%$.
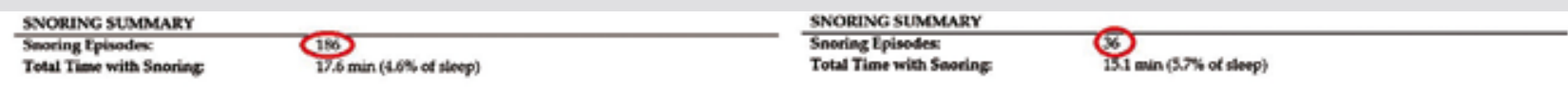

\begin{tabular}{|c|c|c|c|c|c|c|c|c|}
\hline & \multicolumn{2}{|c|}{ WAKE } & \multicolumn{2}{|c|}{ NREM } & \multicolumn{2}{|c|}{ REM } & \multicolumn{2}{|c|}{ Total } \\
\hline Iof Rel Desats & \multicolumn{2}{|c|}{ 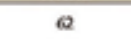 } & \multicolumn{2}{|c|}{$\$ 0$} & \multicolumn{2}{|c|}{90} & \multicolumn{2}{|c|}{612} \\
\hline Mean SpOr: & \multicolumn{2}{|c|}{ (4) } & \multicolumn{2}{|c|}{$\mathbf{N}$} & \multicolumn{2}{|c|}{9} & \multicolumn{2}{|c|}{$\mathbf{4}$} \\
\hline \multicolumn{9}{|l|}{ Fos (mink } \\
\hline & \multicolumn{2}{|c|}{ WAKE. } & \multicolumn{2}{|c|}{ NREM } & \multirow{2}{*}{\multicolumn{2}{|c|}{ RTM }} & \multirow{2}{*}{\multicolumn{2}{|c|}{ TIB }} \\
\hline & \multicolumn{2}{|c|}{ Time } & \multicolumn{2}{|c|}{ Time } & & $T=$ & & \\
\hline & Min & 5 & Min & 5 & Min & $\%$ & Min & $\%$ \\
\hline \multicolumn{9}{|l|}{$e 0 \times$} \\
\hline S5E & 58.5 & 112 & 1672 & 321 & 28.9 & 55 & 2546 & 48.8 \\
\hline $\operatorname{sos}$ & 133 & 26 & 284 & 54 & 77 & 15 & 49.6 & 95 \\
\hline S5\%: & 14 & 03 & 25 & 0.5 & 0.9 & 0.2 & 51 & 10 \\
\hline 500 & 0.0 & 0.0 & 0.0 & 00 & 0.0 & 00 & 00 & $\infty$ \\
\hline $68 \%$ & 00 & 00 & 00 & 00 & 0.0 & 00 & 00 & $\infty$ \\
\hline oosis & 0.0 & 00 & 0.0 & 00 & 0.0 & $\infty 0$ & 00 & $\infty$ \\
\hline $40 \%$ & 00 & 00 & 0.0 & 00 & 0.0 & 80 & 00 & $\infty$ \\
\hline$<\operatorname{son} \alpha$ & 00 & 00 & 0.0 & 00 & 0.0 & 00 & 00 & $\infty$ \\
\hline Antifact/lad Data: & 0.8 & 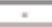 & 03 & 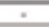 & 0.0 &. & 11 & 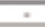 \\
\hline
\end{tabular}

\begin{tabular}{|c|c|c|c|c|c|c|c|c|}
\hline & \multicolumn{2}{|c|}{ WAKE } & \multicolumn{2}{|c|}{ NREM } & \multicolumn{2}{|c|}{ EEM } & \multicolumn{2}{|c|}{ Total } \\
\hline If of Ret Desats & \multicolumn{2}{|c|}{0} & \multicolumn{2}{|c|}{12} & \multicolumn{2}{|c|}{1} & \multicolumn{2}{|c|}{13} \\
\hline Mean SpO2N & & & \multicolumn{2}{|c|}{9} & \multicolumn{2}{|c|}{$\%$} & \multicolumn{2}{|c|}{$\%$} \\
\hline \multicolumn{9}{|l|}{$\cos$ (min): } \\
\hline & \multicolumn{2}{|c|}{ WAKR } & \multicolumn{2}{|c|}{ NREM } & \multicolumn{2}{|c|}{ EEM } & \multicolumn{2}{|c|}{ III } \\
\hline & \multicolumn{2}{|c|}{ Time } & \multicolumn{2}{|c|}{ Tren } & \multicolumn{2}{|c|}{ Time } & \multicolumn{2}{|c|}{ Time } \\
\hline & Min & 8 & Min & 5 & Min & 5 & Min & 5 \\
\hline \multicolumn{9}{|l|}{$e_{k}$} \\
\hline $80 \%$ & 34 & as & 74 & 17 & 02 & 00 & 110 & 25 \\
\hline 200 & 00 & 00 & 0.0 & 0.0 & $\infty$ & 00 & 0.0 & 0.0 \\
\hline $85 \%$ & 00 & 00 & 0.0 & 0.0 & 00 & 00 & 0.0 & 0.0 \\
\hline 20 & 00 & 00 & 0.0 & 0.0 & 00 & 00 & 0.0 & 00 \\
\hline $65 \%$ & 0 & 0.0 & 0.0 & 0.0 & 00 & 00 & 0.0 & 0.0 \\
\hline $20 \%$ & 0 & 0.0 & 0.0 & 0.0 & 00 & 00 & 0.0 & $a$ \\
\hline 2000 & 0.0 & 0.0 & 00 & 0.0 & 0.0 & 00 & 0.0 & 0.0 \\
\hline$<50 \%$ & 00 & 00 & 0.0 & 0.0 & 00 & 00 & 0.0 & 0.0 \\
\hline Artififad/Bad Datec & 274 & - & 835 & - & 140 & - & 129.9 & - \\
\hline
\end{tabular}

points on the Epworth questionnaire we observed an important decrease to 7 after surgery.

\section{Case 2}

A 48-year-old male patient, obese class I $(176 \mathrm{~cm}$, $97 \mathrm{Kg}, \mathrm{BMI}=31.31)$, referred to our department complaining of ronhopaty and sleep apnea syndrome (both reported by his wife), daytime sleepiness $($ Epworth Score $=15)$. Also, the patient reported progressive decreased ability to work.

The clinical and paraclinical (naso-pharyngolaryngo videoendoscopy) examinations revealed a moderate hypertrophy of the inferior turbinates (significant volume reduction after 1 month of topic corticoid solutions), medio-sagittal nasal septum, long soft palate and large uvula, with secondary shrinking of the oropharyngeal isthmus - Class
III Mallampati scale. Normal aspect of the tonsils and eutrophic hypopharynx and larynx.

In order to obtain a correct diagnosis of the pathology, we performed an initial polysomnography that revealed moderate sleep apnea $(\mathrm{AHI}=15.8 / \mathrm{h})$, with a total REM sleep of 18 minutes (maybe due to the "first-night effect" sleep), sleep efficiency of $69.1 \%$ from a total of 392.5 minutes of Sleep Period Time and 319 minutes of Total Sleep Time, 258 arousals, mean SpO2 of $94 \%$ and minimum SpO2 of $90 \%$ (Tables 10-13). A total of 84 obstructive sleep events were recorded, out of which 35 were obstructive apneas, 5 central apneas, 10 mixed apneas, and 34 hypopneas. The maximum duration of an obstructive event was 44 seconds (Table 12). The snoring episodes number was 318 , with a total duration of 100 minutes (Table 11). 

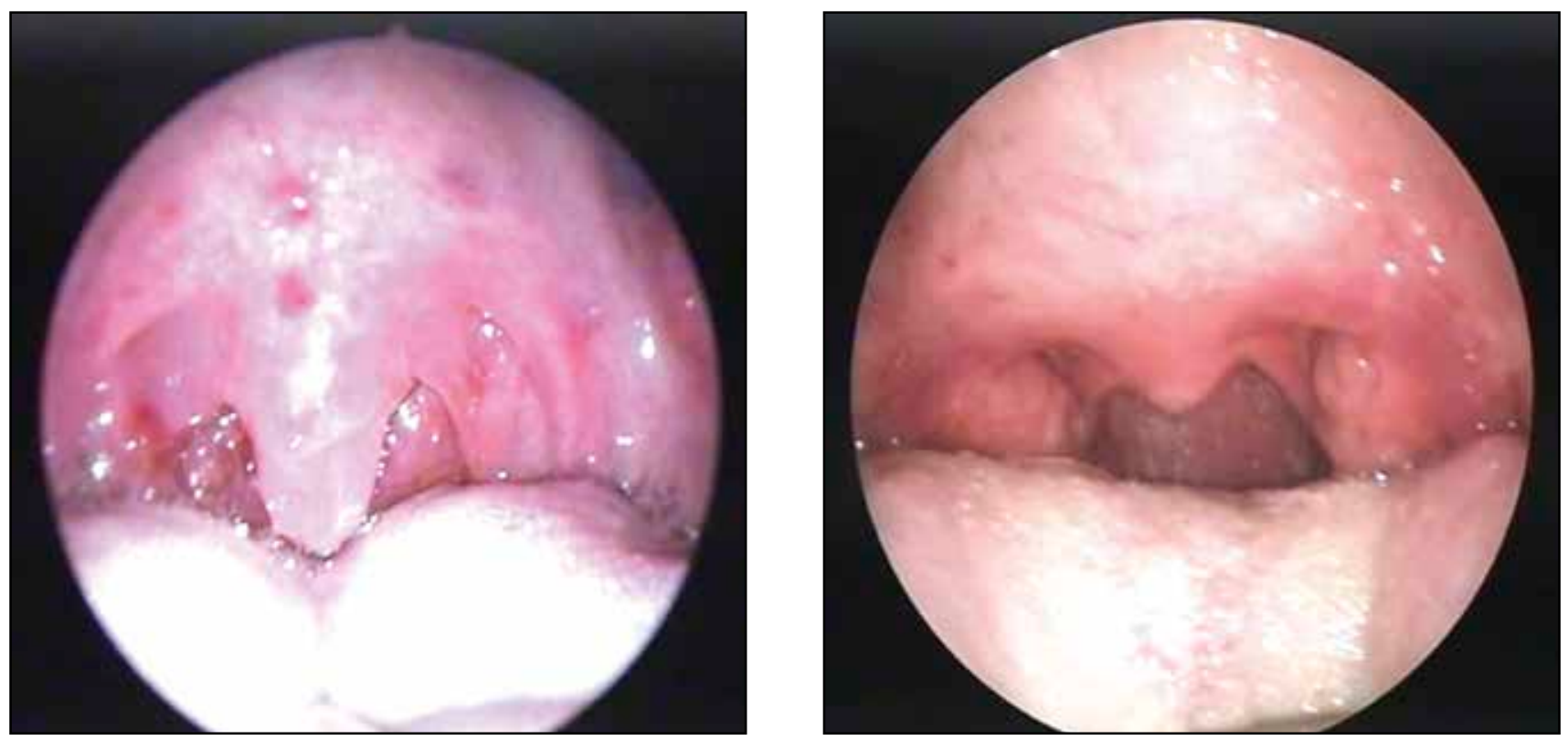

Figure 7 Preoperative aspect of the uvula and the soft palate and 1 month post LAUP with complete healing and improvement of the size of the respiratory tract.

\section{Table 10}

After LAUP surgery (6 months postoperatively) the Sleep Staging had an important improvement; REM sleep increased from 18 minutes initially to 85 .

\begin{tabular}{|c|c|c|c|c|}
\hline \multicolumn{5}{|c|}{ SLEEP ARCHITECTURE } \\
\hline \multicolumn{3}{|c|}{ Lights off dock time: } & & $957.30 \mathrm{FM}$ \\
\hline \multicolumn{3}{|c|}{ Lights on dock times } & & $561: 12$ AM \\
\hline \multicolumn{3}{|c|}{ Total Recording Time (TRT): } & & $\$ 61.7$ minutes \\
\hline \multicolumn{3}{|c|}{ Time In Bed (TIB) } & & 461.7 minutes \\
\hline \multicolumn{3}{|c|}{ Sleep Period Time (SPT): } & & 392.5 minutes \\
\hline \multicolumn{3}{|c|}{ Total Sleep Time (TST) } & & 319.0 minutes \\
\hline \multicolumn{3}{|c|}{ Sleep Etficiency: } & & $69.1 \%$ \\
\hline \multicolumn{3}{|l|}{ Sleep Onset: } & & 22.5 minutes \\
\hline \multirow{2}{*}{\multicolumn{3}{|c|}{$\begin{array}{l}\text { REM Lateacy Utrom Sleep Onse0: } \\
\text { REM Latency throm Lights Otf: }\end{array}$}} & & 75 minutes \\
\hline & & & & 30.0 minutes \\
\hline Steep Stapiant & Duration & \$ TST & Late & \\
\hline N1: & 1695 pinutes & $531 \%$ & Ni: & 22.5 minutes \\
\hline N2: & 1005 thinutes & $337 \%$ & $\mathrm{~N}_{2}$ & 340 mateutes \\
\hline N3: & 240 plinutes & $7.5 \%$ & N9 & 520 minutes \\
\hline R: & hinutes & $5.6 \%$ & R: & 300 manutes \\
\hline
\end{tabular}

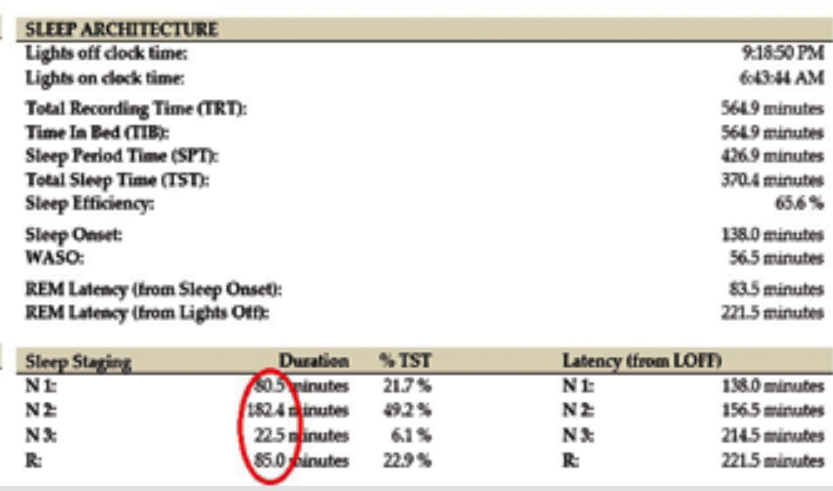

Laser-assisted uvulopalatoplasty (LAUP) was performed under local anaesthesia without any premedication. For local anaesthesia we used $10 \%$ lidocaine spray that was applied to the soft palate, followed by infiltration on either side of the base of the uvula and soft palate area with mixture of lidocaine $2 \%$ and adrenaline. The LASER diode must be set on $15 \mathrm{~W}$ in continuous mode and also Radiofrequency was used to produce thermal lesions within the tissues in order to stiffen the neosoft palate (Figure 7).

The subjective result was marked by pre- and postoperative daytime sleepiness index on Epworth questionnaire. We recorded a decreasing score from 13 to 5 six months after the LAUP surgery.

At the 6-month evaluation after the LAUP surgery, we recorded a significant improvement in symptoms, consisting of a decrease in the AHI index from $15.8 / \mathrm{h}$ initially to $2.3 / \mathrm{h}$ (Table 11 ). The total number of 84 obstructive events decreased after surgery to a total of 14 events. The maximum duration of a respiratory event also improved from 44 seconds initially to 16 seconds. The number of obstructive sleep apneas was significantly reduced from 35 events initially to a number of 4 events postoperatively (Table 12). Another factor that makes us confident that this procedure is a real success is represented by the decreased 
Table 11

The minimum SpO2 improved with 2 percent from 90 to $92 \%$ and the snoring episodes decreased from 318 to 27 events.

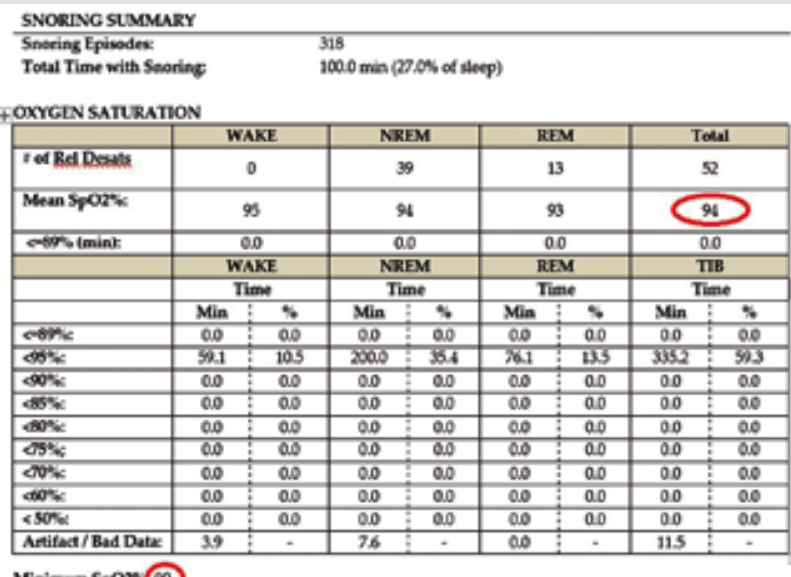

Minimespors 90

OXYGEN SiTURATION DESTREUTON
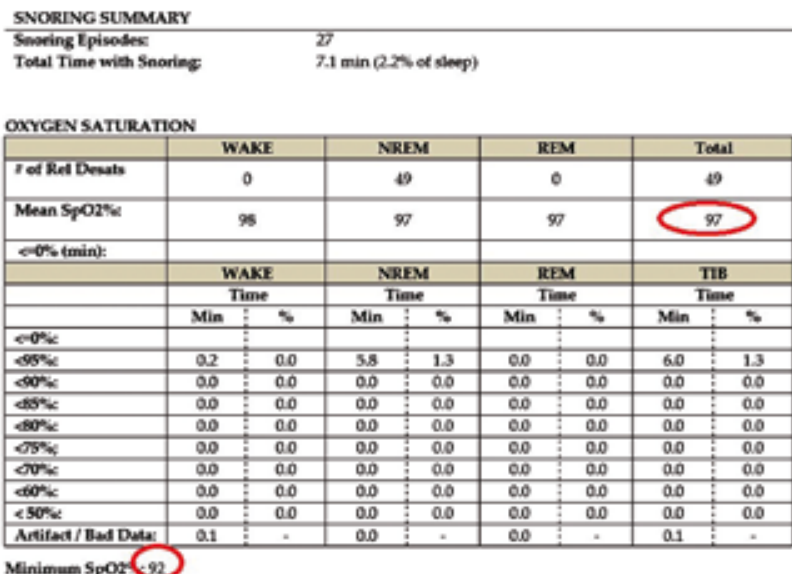

Minimum 5 por $(22$

OXYGEN SATURATION DESTRISUTION

Table 12

The evolution of sleeping events before and after LAUP.

\begin{tabular}{|c|c|c|c|c|c|c|c|c|}
\hline & $\mathrm{Ca}$ & $\mathrm{OA}$ & MA & Apnea & Hypog" & $A+\mathrm{H}$ & RERA & Tobal \\
\hline Number. & 5 & (35) & 10 & 50 & 34 & 84 & 0 & (34) \\
\hline Mean Derr (sed: & 20.5 & 24 & 33.4 & 25.9 & 22.1 & 244 & 0.0 & 24.4 \\
\hline Max Der (sec): & 300 & 375 & 40 & 450 & 335 & 40 & 0.0 & 440 \\
\hline Told Dur (min): & 18 & 142 & 56 & 21.6 & 125 & 341 & 0.0 & 34.1 \\
\hline \% of TST: & 0.6 & 4.5 & 17 & 6.8 & 39 & 107 & 00 & 107 \\
\hline Index (tth TSD): & 0.9 & 66 & 19 & 94 & 64 & 15.8 & 0.0 & \\
\hline REM Count: & 0 & 2 & 1 & 3 & 0 & 3 & 0 & 3 \\
\hline NREM Count: & 5 & 32 & 9 & 46 & 31 & $\pi$ & 0 & $\pi$ \\
\hline REM Lndex & 0.0 & 67 & 33 & 100 & 0.0 & 100 & 0.0 & 1000 \\
\hline NREM Index & 10 & 6.4 & 1.8 & 9.2 & 62 & 153 & 0.0 & 153 \\
\hline
\end{tabular}

\begin{tabular}{|c|c|c|c|c|c|c|c|c|}
\hline & CA & 24 & MA & Aptoses & Hyrop" & $A+H$ & RERA & Intel \\
\hline Number & 1 & (4) & 0 & 5 & 9 & 14 & 0 & 14 \\
\hline Mean Dur (seck: & 120 & 113 & 000 & 11.4 & 124 & 120 & 0.0 & 120 \\
\hline Max Dur Gect: & 120 & 12.5 & 0.0 & 12.5 & (6) & 160 & 0.0 & 360 \\
\hline Total Dur $(\min )$ : & 02 & 0.5 & 0.0 & 09 & 1.9 & 28 & 0.0 & 28 \\
\hline Sof TST: & 0.1 & 0.2 & 0.0 & 0.3 & 0.5 & 0.8 & 00 & o.s \\
\hline Index $(\tan$ TSD): & 02 & 0.6 & 0.0 & 0.8 & 1.5 & 23 & 00 & 23 \\
\hline REM Count: & 0 & 1 & 0 & 1 & 1 & 2 & 0 & 2 \\
\hline NREM Count & 1 & 3 & 0 & 4 & 8 & 12 & 0 & 12 \\
\hline REM Index & 0.0 & $\alpha 7$ & 0.0 & 0.7 & a 7 & 14 & 0.0 & 14 \\
\hline NREM ladex & 02 & 0.6 & 0.0 & 0.8 & 1.7 & 25 & 0.0 & 25 \\
\hline
\end{tabular}

duration of respiratory events.

When it comes to snoring, spectacular results were notified. Starting from 318 events initially (100 minutes), numbers went down to 27 events (7.1 minutes) (Table 11). Subsidiary to these modifications, the $\mathrm{SpO}_{2}$ level grew from 90 - 92\% (minimum saturation) to $94-97 \%$ (medium saturation) (Table 11).

The sleep architecture also registered an important improvement stage N1 from 169.5 minutes $(53.1 \%)$ to 80.5 minutes (representing $21.7 \%$ from the total sleep time), N2 from 107.5 minutes $(33.7 \%)$ to 182.4 minutes $(49.2 \%)$, N3 from 24.0 minutes $(7.5 \%)$ to 22.5 minutes $(6.1 \%)$ and REM

sleep from a total of 18.0 minutes $(5.6 \%)$ to 85.0 $(22.9 \%$ ) (Table 10$)$. The total sleep recording time was different. At the initial investigation $461.7 \mathrm{~min}$ utes were monitored; meanwhile, at the postoperative investigation we monitored approximately 564.9 minutes, but the sleep time period was similar (392.5 minutes preoperatively and 426.9 minutes postoperatively). The arousal index decreased from $38.5 / \mathrm{h}$ to $6.7 / \mathrm{h}$, from a total events number of 258 to 38 (Table 13). We believe that the arousal index is very important in the deep sleep architecture and that is the reason we obtained such improvement.

Another reason for the better results that we ob- 


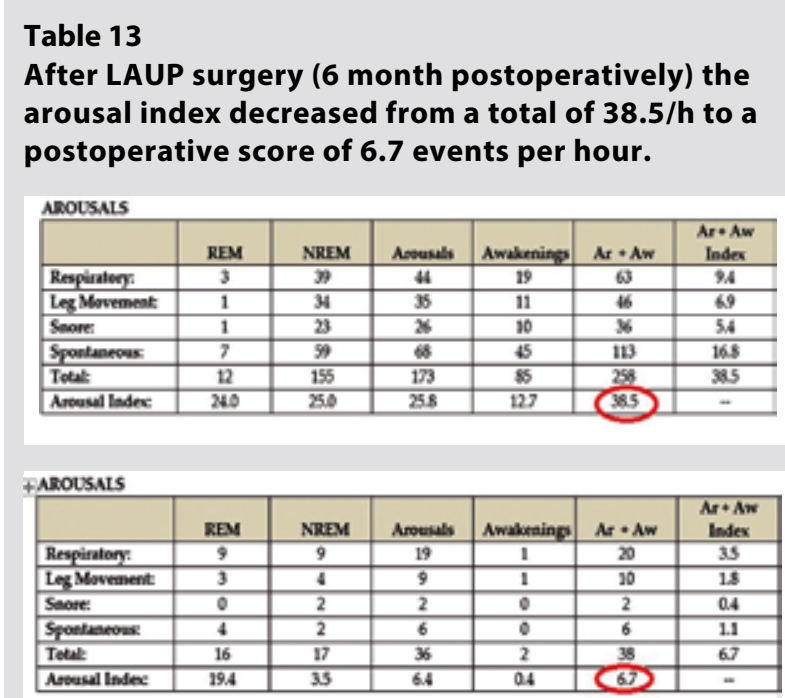

tained might be the body mass index improvement from 31 to 27.1 (from obesity grade I to overweight) 6 months postoperatively.

\section{DISCUSSIONS}

Although in the specialty literature we can find numerous studies which prove the benefit of the nasopharyngeal repermeabilization surgery, there are also contradictory results. When discussing about obstructive sleep apnea, we believe that, with a careful selection of patients, the results can be satisfactory. A literature review was performed for the identification of options for surgical treatments modalities for adults with the sleep apnea syndrome $^{10-12}$.

One of the most common and also challenging treatments for the otorhinolaryngologist is the nasal repermeabilization surgery. The correction of the nasal obstruction is considered a component of the obstructive sleep apnea treatment ${ }^{13}$.

In the pathogenesis of OSA, we do not know the precise role of the nasal airway obstruction, but the mechanism is well established, taking into consideration that lowering the nasal cross-sectional area determines an increase in nasal resistance and the patient is predisposed to inspiratory collapse of the oropharynx, hypopharynx, or both of them ${ }^{14}$.

In the current literature, we found a lot of controversial data regarding the role of improved nasal breathing in the treatment of OSA. Series et al. reveals on a group of 20 patients diagnosed and treated for nasal obstruction, an important improvement regarding the nasal obstruction but poor improvement in the apnea/hypopnea index
(AHI) from $39.8+/-6.1 / \mathrm{h}$ to $36.8+/-5.9 / \mathrm{h}^{15}$.

On the other hand, $\mathrm{Li}$ et al. revealed a much greater importance of the nasal repermeabilization surgery in order to treat OSA - from an initial AHI of $35+/-22.6 / \mathrm{h}$ to $33.5+/-23.8 / \mathrm{h}$, with a success rate of almost 17 percent $^{16}$. Our study also reveals an important impact of the nasal surgery upon OSA symptoms.

Sher et al. describe that most of the patients with sleep breathing disorders have abnormal structures of the upper airway system. We assumed that an important role in the sleep apnea appearance is played by the soft palate and the uvula because of their specific locations ${ }^{17}$.

Responsible for the breathing disorders seems to be the abnormal movement of the soft palate and the uvula that were observed during sleep in OSAS patients. Because of the specific location at the entrance of the palatopharynx and also due to their orientations, the soft palate and the uvula are critical for respiration ${ }^{18}$.

In order to avoid the pharyngeal collapse, many procedures were proposed ${ }^{19}$. In this study we focused on laser-assisted uvulopalatoplasty (LAUP), which is considered to be a safer, more economical and more comfortable alternative to other surgery procedures with the same indication ${ }^{20}$.

LASER uvulopalatoplasty is an in-office procedure assisted with LASER tools, in order to shape the soft palate and the uvula, and it was initially described as treatment for snoring; the procedure was subsequently applied as treatment for sleep apnea $^{21}$.

In 1990, Haraldsson reported his initial experiences with LAUP as a treatment modality that is more easily performed under local anaesthesia ${ }^{22}$.

According to the current literature, snoring can be significantly reduced to an unnoticed level with the repeated administration of radiofrequency energy to the soft palate ${ }^{23}$.

Studying the literature, we see that although the data are relatively different, in most cases the AHI score decreases after LAUP. Also, the patient's attitude is important and it is represented by a decrease in the body mass index (BMI) ${ }^{24-32}$ (Table 14). Contradictory results are presented by Berger in 2003. In his study, which included 25 patients, the AHI score raised with 31 percent after LAUP ${ }^{28}$ (Table 14).

Taking into consideration the possible postoperative complications rate available in the literature (classified as minor complications - mucosal erosions or ulcerations or prolonged dysphagia, moderate complications - palatal fistula or uvula loss, severe complications - secondary hospital admission for life-threatening events), we reported 
only minor complications such as continuous odynophagia and 1 patient with mucosal erosion solved with specific treatment ${ }^{32}$.

In order for a patient to undergo LAUP as treatment for snoring, they must be clinically evaluated before surgery and should undergo a polysomnographic or a cardiorespiratory study to be able to make a differential diagnosis between various sleep disorders, even with $\mathrm{OSA}^{33}$.

Because snoring is frequently the main diagnostic symptom, the necessity for periodically monitoring the patient in order to ascertain the subsequent development of obstructive sleep apnea should be properly reinforced even if the procedure reduces or eliminates snoring ${ }^{34}$.

In order to select patients that are viable candidates for this intervention, they must undergo a series of clinical and paraclinical investigations such as the patient's medical history, the assessment of inspiration using the Müller's manoeuvre, questionnaire data, the endoscopic examination of the nasopharynx, a polysomnography, and various imaging studies ${ }^{35}$. When it comes to the preoperative selection process for this procedure, there are multiple points of view. A few investigators suggested that imaging studies or decision algorithms should be used in order to locate the site of obstruction, but there is no unanimity among them ${ }^{36}$.

When settling on LAUP as the main intervention for snoring, a major sleep-related breathing disorder such as obstructive sleep apnea should be always taken into account. The clinical examination can be undependable. The information gathered by the physician during the clinical history and the physical examination shapes a subjective assess- ment regarding whether a patient does or does not have OSA, offering a correct identification in 52\% of the patients with OSA and a specificity of $70 \%{ }^{37}$.

Meanwhile, in other studies, it was shown that out of the 73 patients that applied for LAUP treatment, $69(95 \%)$ had obstructive sleep apnea according to the polysomnography, although $41 \%$ presented with snoring as the only symptom ${ }^{38}$.

Furthermore, when evaluating the correlation between the patient's subjective rating for snoring loudness, frequency and consequences and the objective respiratory variables obtained by polysomnography, we noticed the discrepancy between the two. When taking into consideration everything mentioned above, if we consider LAUP as primary treatment for snoring, the patient should be assessed for OSA by using polysomnography or Level III recording. A Level III recording, also known as cardiorespiratory study, consists of a minimum of four channels with recording of oximetry, heart rate or ECG and at least two respiratory effort channels or a respiratory effort channel and an airflow channel ${ }^{39}$.

In a study published in 2017 , we demonstrated the effect of the permeabilization surgery of the upper respiratory tract upon sleep fragmentation and REM sleep. The PSG performed 6 months after the surgical interventions revealed a decrease in the arousal index and a better REM sleep score (decrease of Stage 1 and Stage 2) ${ }^{40}$.

Patients meant to undergo nasopharyngeal repermeabilization surgery are considered to be the ones diagnosed with mild and moderate OSA and for patients with severe OSA the procedure is meant to raise the patients' compliance with

Table 14

PSG results before and after LAUP for OSA.

\begin{tabular}{|c|c|c|c|c|c|c|c|c|}
\hline Study authors, year & Number & Age & Body mass index & Pre-op AHI & Post-op AHI & AHI change & Pre-OP LSAT & Post-OP LSAT \\
\hline Goktas, $2014^{24}$ & 23 & 63 & $30 \pm 4$ & $28 \pm 17$ & $25 \pm 20$ & $-12 \%$ & - & - \\
\hline Chisholm, $2007^{25}$ & 20 & - & $32(28-38)$ & $48 \pm 20$ & $13 \pm 11$ & $-73 \%$ & - & - \\
\hline Pavelec, $2006^{26}$ & 63 & $20-67$ & - & $7 \pm 6$ & $5 \pm 4$ & $-32 \%$ & - & - \\
\hline Berger, $2003^{28}$ & 25 & $50 \pm 10$ & $28 \pm 3$ & $25 \pm 14$ & $33 \pm 23$ & $+31 \%$ & $88 \pm 6$ & $85 \pm 9$ \\
\hline Kern, $2004^{27}$ & 64 & $43 \pm 11$ & $27 \pm 4$ & $51 \pm 31$ & $26 \pm 21$ & $-49 \%$ & $77 \pm 13$ & $84 \pm 10$ \\
\hline Finkelstein, $2002^{29}$ & 26 & $53 \pm 10$ & $28 \pm 3$ & $30 \pm 22$ & $25 \pm 19$ & $-16 \%$ & $86 \pm 9$ & $87 \pm 8$ \\
\hline Lin, $2002^{30}$ & 25 & $41 \pm 6$ & $28 \pm 2$ & $40 \pm 7$ & $32 \pm 14$ & $-21 \%$ & $71 \pm 5$ & $76 \pm 9$ \\
\hline Ryan, $2000^{8}$ & 44 & $49 \pm 11$ & $30 \pm 4$ & $29 \pm 17$ & $19 \pm 15$ & $-34 \%$ & $78 \pm 12$ & $81 \pm 9$ \\
\hline Mickelson, $1999^{31}$ & 36 & $52 \pm 11$ & $31 \pm 8$ & $28 \pm 17$ & $18 \pm 14$ & $-36 \%$ & $81 \pm 10$ & $84 \pm 7$ \\
\hline Walker, 199932 & 40 & $53 \pm 2$ & $31 \pm 1$ & $25 \pm 3$ & $15 \pm 3$ & $-39 \%$ & $84 \pm 1$ & $85 \pm 1$ \\
\hline
\end{tabular}


CPAP therapy.

Very important when taking into consideration the treatment for patients with sleep apnea is the patients' attitude toward weight loss, this being a key element when treating this type of pathology.

We believe that CPAP therapy is the gold standard in the treatment of OSA-diagnosed patients, but the nasopharyngeal repermeabilization surgery is a viable alternative for patients who are not compliant with the ventilation therapy.

\section{CONCLUSIONS}

The advantages of the nasopharyngeal repermeabilization surgery are represented by decreasing the severity of respiratory events and, second to this, lowering the number of arousals. By reducing the number of arousals we will obtain a better percentage regarding the deep sleep phase REM, having a beneficial effect on reducing the daytime sleepiness - which is a major symptom that patients present.

Upper airway tract surgery for sleep breathing disorders may be a viable option for patients who refuse the continuous positive pressure therapy.

Polysomnography is the reference investigation for both the diagnosis and for a correct conducted therapy for patients suffering from respiratory disorders during sleep.

Respiratory tract repermeabilization surgery prior to non-invasive ventilation at domicile increases patient's compliance with the treatment.

Selected patients' cases responded favourably post-surgically, while the polysomnographic investigation showed the opposite but also the reverse direction.

Surgery for upper respiratory tract reperfusion therapy represents a component of a global management plan.

Conflict of interest: The authors have no conflict of interest.

Contribution of authors: All authors have equally contributed to this work.

\section{REFERENCES}

1. Peppard PE, Young T, Barnet JH, Palta M, Hagen EW, Hla KM. Increased prevalence of sleep-disordered breathing in adults. Am J Epidemiol. 2013;177(9):1006-14. DOI: 10.1093/aje/kws.342. Epub 2013 Apr 14.

2. Miljeteig $\mathrm{H}$, Hoffstein V. Determinants of continuous positive airway pressure level for treatment of obstructive sleep apnea. Am Rev Respir Dis. 1993;147(6 Pt 1):1526-30.

3. Sullivan CE, Berthon-Jones M, Issa FG, Eves L. Reversal of obstruc- tive sleep apnoea by continuous positive airway pressure applied through the nares. Lancet. 1981;317(8225):862-5. DOI: 10.1016/ S0140-6736(81)92140-1

4. Fujita S, Conway W, Zorick F, Roth T. Surgical correction of anatomic abnormalities in obstructive $\underline{\text { sleep }}$ apnea syndrome: uvulopalatopharyngoplasty. Otolaryngol Head Neck Surg. 1981;89(6):923-34.

5. Walker RP, Grigg-Damberger MM, Gopalsami C. Uvulopalatopharyngoplasty versus laser-assisted uvulopalatoplasty for the treatment of obstructive sleep apnea. Laryngoscope. 1997;107(1):76-82.

6. Lysdahl M, Haraldsson PO. Uvulopalatopharyngoplasty versus laser uvulopalatoplasty: prospective long-term follow-up of self-reported symptoms. Acta Otolaryngol. 2002;122(7):752-7.

7. Lin CC, Lee KS, Chang KC, Wu KM, Chou CS. Effect of laser-assisted uvulopalatoplasty on oral airway resistance during wakefulness in obstructive sleep apnea syndrome. Eur Arch Otorhinolaryngol. 2006;263(3):241-7. DOI: 10.1007/s00405-0050994-2. Epub 2005 Sep 15.

8. Ryan CF, Love LL. Unpredictable results of laser assisted uvulopala$\underline{\text { toplasty }}$ in the treatment of obstructive sleep apnoea. Thorax. 2000;55(5):399-404.

9. Agency for Health Care Policy and Research. Polysomnography and sleep disorders centers. AHCPR Publication No. 92-0027. Health Technol Assess Rep. 1991;4:1-22.

10. Troell RJ, Riley RW, Powell NB, Li K. Surgical management of the hypopharyngeal airway in sleep disordered breathing. Otolaryngol Clin North Am. 1998;31 (6): 979-1012.

11. Lin HC, Friedman M, Chang HW, Gurpinar B. The efficacy of multilevel surgery of the upper airway in adults with obstructive sleep apnea/hypopnea syndrome. Laryngoscope. 2008;118(5):902-8. DOI: 10.1097/MLG.0b013e31816422ea.

12. Caples SM, Rowley JA, Prinsell JR, Pallanch JF, Elamin MB, Katz SG, et al. Surgical modifications of the upper airway for obstructive sleep apnea in adults: a systematic review and meta-analysis. Sleep. 2010;33(10):1396-407.

13. Dayal VS, Phillipson EA. Nasal surgery in the management of sleep apnea. Ann Otol Rhinol Laryngol. 1985;94(6 Pt 1):550-4.

14. Olsen KD, Kern EB, Westbrook PR. Sleep and breathing disturbance $\frac{\text { secondary }}{\text { to }}$ nasal obstruction. Otolaryngol Head Neck Surg. 1981;89(5):804-10.

15. Sériès F, St Pierre S, Carrier G. Effects of surgical correction of nasal obstruction in the treatment of obstructive sleep apnea. Am Rev Respir Dis. 1992;146(5 Pt 1):1261-5. DOI: 10.1164/ ajrccm/146.5Pt1.1261.

16. Li HY, Wang PC, Chen YP, Lee LA, Fang TJ, Lin HC. Critical appraisal and meta-analysis of nasal surgery for obstructive sleep apnea. Am J Rhinol Allergy. 2011;25(1):45-9. DOI: 10.2500/ ajra.2011.25.3558.

17. Sher AE, Schechtman KB, Piccirillo JF. The efficacy of surgical modifications of the upper airway in adults with obstructive sleep apnea syndrome. Sleep. 1996;19(2):156-77.

18. Li Y, Lin N, Ye J, Chang Q, Han D, Sperry A. Upper airway fat tissue distribution in subjects with obstructive sleep apnea and its effect on retropalatal mechanical loads. Respir Care. 2012;57(7):1098-105. DOI: 10.4187/respcare.00920. Epub 2012 Jan 23.

19. Ryan CF. Laser assisted uvulopalatoplasty in sleep disordered breathing. Thorax. 1997;52(1):5-8.

20. Lauretano AM, Khosla RK, Richardson CT, Matheson J, Weiss JW, Graham C, et al. Efficacy of laser-assisted uvulopalatoplasty. Lasers Surg Med. 1997;21 (2):109-16.

21. Kamami YV. Laser CO2 for snoring. Preliminary results. Acta Oto- 
rhinolaryngol Belg. 1990;44(4):451-6.

22. Haraldsson PO, Carenfelt C. Laser uvulopalatoplasty in local anaesthesia. A safe approach in the treatment of habitual snoring. Rhinology. 1990;28(1):65-6.

23. Walker RP, Gatti WM, Poirer N, Davis JS. Objective assessment of snoring before and after laser-assisted uvulopalatoplasty. Laryngoscope. 1996;106(11):1372-7.

24. Goktas O, Solmaz M, Goktas G, Olze H. Long-Term Results in Obstructive Sleep Apnea Syndrome (OSAS) after Laser-Assisted Uvulopalatoplasty (LAUP). PLoS One. 2014;9(6):e100211. DOI: 10.1371/ journal.pone.0100211.

25. Chisholm E, Kotecha B. Oropharyngeal surgery for obstructive sleep apnoea in CPAP failures. Eu Arch Otorhinolaryngol. 2007;264(1):515. Epub 2006 Aug 31.

26. Pavelec V, Polenik P. Use of Er,Cr:YSGG versus standard lasers in laser assited uvulopalatoplasty for treatment of snoring. Laryngoscope. 2006;116(8):1512-6.

27. Kern RC, Kutler D, Reid Kj, Conley DB, Herzon GD, Zee P._Laserassisted uvulopalatoplasty and tonsillectomy for the management of obstructive sleep apnea syndrome. Laryngoscope. 2003;113(7):1175-81.

28. Berger G, Stein G, Ophir D, Finkelstein Y. Is there a better way to do laser-assisted uvulopalatoplasty? Arch Otolaryngol Head Neck Surg. 2003;129(4):447-53.

29. Finkelstein Y, Stein G, Ophir D, Berger R, Berger G.Laser-assisted uvulopalatoplasty for the management of obstructive sleep apnea: myths and facts. Arcg Otolaryngol Head Neck Surg. 2002;128(4):429-34.

30. Lin CC, Chang KC, Lee KS. Effects of treatment by lasser-assissted uvuloplasty on sleep energy expenditure in obstructive sleep apnea patients. Metabolism. 2002;51(5):622-7.

31. Mickelson SA, Ahuja A. Short-term objective and long-term subjec- tive results of laser-assisted uvulopalatoplasty for obstructive sleep apnea. Laryngoscope. 1999;109(3):362-7.

32. Walker RP, Gopalsami C. Laser-assisted uvulopalatoplasty: postoperative complications. Laryngoscope. 1996;106(7):834-8.

33. Hörmann K, Verse T. Surgery for Sleep Disordered Breathing. Springer-Verlag Berlin Heidelberg; 2010.

34. Ellis PD, Williams JE, Shneerson JM. Surgical relief of snoring due to palatal flutter: a preliminary report. Ann R Coll Surg Engl. 1993;75(4):286-90.

35. Epstein LJ, Kristo D, Strollo PJ Jr, Friedman N, Malhotra A, Patil SP, et al. Clinical guideline for the evaluation, management and longterm care of obstructive sleep apnea in adults. J Clin Sleep Med. 2009;5(3):263-76.

36. Tsushima U, Antila J, Laurikainen E, Svedström E, Polo O, Kormano M. Digital fluoroscopy before and after laser uvulopalatopharyngoplasty in obstructive sleep apnea. Importance of pharyngeal collapsibility and hyoid bone position. Acta Radiol. 1997;38(2):214-21.

37. Utley DS, Shin EJ, Clerk AA, Terris DJ. A cost-effective and rational surgical approach to patients with snoring, upper airway resistance syndrome, or obstructive sleep apnea syndrome. Laryngoscope. 1997;107(6):726-34.

38. Khosh M, Keidar A, Zammit GK, Krespi YP. Self-reported symptoms and polysomnographic findings in laser-assisted uvulopalatoplasty candidates. Otolaryngol Head Neck Surg. 1994;43 (Abstract).

39. Practice parameters for the indications for polysomnography and related procedures. Polysomnography Task Force, American Sleep Disorders Association Standards of Practice Committee. Sleep. 1997;20(6):406-22

40. Tanase I, Manea C, Sarafoleanu C. Permeabilization surgery of the upper respiratory tract and its effects on sleep fragmentation and REM sleep. Romanian Journal of Rhinology. 2017;7(25);47-56. DOI 10.1515/rjr-2017-0006. 